\title{
Same-admission versus delayed cholecystectomy for mild acute biliary pancreatitis: a systematic review and meta- analysis
}

Yun-Xiao Lyu* (D), Yun-Xiao Cheng, Hang-Fei Jin, Xin Jin, Bin Cheng and Dian Lu

\begin{abstract}
Background: The timing of laparoscopic cholecystectomy (LC) performed after the mild acute biliary pancreatitis (MABP) is still controversial. We conducted a review to compare same-admission laparoscopic cholecystectomy (SA-LC) and delayed laparoscopic cholecystectomy (DLC) after mild acute biliary pancreatitis (MABP).

Methods: We systematically searched several databases (PubMed, EMBASE, Web of Science, and the Cochrane Library) for relevant trials published from 1 January 1992 to 1 June 2018. Human prospective or retrospective studies that compared SA-LC and DLC after MABP were included. The measured outcomes were the rate of conversion to open cholecystectomy (COC), rate of postoperative complications, rate of biliary-related complications, operative time (OT), and length of stay (LOS). The meta-analysis was performed using Review Manager 5.3 software (The Cochrane Collaboration, Oxford, United Kingdom).

Results: This meta-analysis involved 1833 patients from 4 randomized controlled trials and 7 retrospective studies. No significant differences were found in the rate of COC (risk ratio $[\mathrm{RR}]=1.24 ; 95 \%$ confidence interval [Cl], 0. 78-1.97; $p=0.36$ ), rate of postoperative complications ( $R R=1.06 ; 95 \% \mathrm{Cl}, 0.67-1.69 ; p=0.80$ ), rate of biliary -related complications ( $\mathrm{RR}=1.28 ; 95 \% \mathrm{Cl}, 0.42-3.86 ; p=0.66)$, or $\mathrm{OT}(\mathrm{RR}=1.57 ; 95 \% \mathrm{Cl},-1.58-4.72 ; p=0.33)$ between the SA-LC and DLC groups. The LOS was significantly longer in the DLC group (RR $=-2.08 ; 95 \% \mathrm{Cl},-3.17$ to $-0.99 ; p=0.0002$ ). Unexpectedly, the subgroup analysis showed no significant difference in LOS according to the Atlanta classification ( $R R=-0.40 ; 95 \% \mathrm{Cl},-0.80-0.01 ; p=0.05$ ). The gallstone-related complications during the waiting time in the DLC group included gall colic, recurrent pancreatitis, acute cholecystitis, jaundice, and acute cholangitis (total, 25.39\%).
\end{abstract}

Conclusion: This study confirms the safety of SA-LC, which could shorten the LOS. However, the study findings have a number of important implications for future practice.

Keywords: Pancreatitis, Cholecystectomy, Laparoscopic, Review, Meta-analysis

\footnotetext{
* Correspondence: Ivyunxiao1986@gmail.com

Department of Hepatobiliary Surgery, Dongyang People's Hospital, 60 West

Wuning Road, 322100, Dongyang, Zhejiang, China
}

(c) The Author(s). 2018 Open Access This article is distributed under the terms of the Creative Commons Attribution 4.0 International License (http://creativecommons.org/licenses/by/4.0/), which permits unrestricted use, distribution, and reproduction in any medium, provided you give appropriate credit to the original author(s) and the source, provide a link to the Creative Commons license, and indicate if changes were made. The Creative Commons Public Domain Dedication waiver (http://creativecommons.org/publicdomain/zero/1.0/) applies to the data made available in this article, unless otherwise stated. 


\section{Background}

Acute pancreatitis is a common disease in the emergency room with an annual incidence ranging from 4.9 to 35 per 100,000 population [1]. According to the Atlanta classification, $80 \%$ of patients with pancreatitis have mild acute pancreatitis [2]. Acute biliary pancreatitis is one of the most common types of acute pancreatitis, accounting for up to 40 to $70 \%$ of cases [3-5].

Cholecystectomy is considered to be effective in reducing the recurrence of acute gallstone pancreatitis [6-8]. Previous studies have shown that the probability of recurrence of acute pancreatitis without cholecystectomy is as high as $33 \%$ [9]. However, a primary concern in the treatment of mild acute biliary pancreatitis (MABP) is the optimal timing of LC. A previous review showed that delayed cholecystectomy can increase readmission [10-12]. However, most guidelines advise early LC after MABP [12-14]. Early LC can reduce the risk of recurrent biliary events [15]. However, many previous studies had low methodological quality. One of the heterogeneities is the previous study using different criteria for the severity of pancreatitis. We defined same-admission LC (SA-LC) as LC performed within the same admission after MABP. A nationwide randomized study was recently published [16]. The aim of this study was to compare SA-LC and DLC after MABP through analysis including recently studies.

\section{Methods}

\section{Search strategy}

Two authors independently performed a systematic review of PubMed, Embase, Web of Science, and the Cochrane Library from 1 January 1992 to 1 June 2018. The search terms were "cholecystectomy," "pancreatitis," "laparoscopy," and "laparoscopic cholecystectomy." In this meta-analysis, we defined SA-LC as initial LC performed during the same admission because of MABP. The control group underwent DLC at readmission. The references of the articles identified after the initial search were also manually reviewed. The language in the search was limited to English. This meta-analysis adhered to the PRISMA statement [17].

\section{Inclusion and exclusion criteria}

We applied the following inclusion criteria: (1) trials comparing the clinical outcomes of interest between SA-LC and DLC, (2) studies with a clear MABP severity scoring system, and (3) studies that provided adequate data on the clinical outcomes.

We excluded studies that (1) were review articles, case reports, abstracts, editorials, and letters to the editor; (2) included patients with severe pancreatitis and pancreatitis of other origins.

\section{Outcomes of interest}

The outcome measures were the rate of conversion to open cholecystectomy (COC), operative time (OT), length of stay (LOS), rate of postoperative complications, and rate of biliary-related complications. Biliary-related complications were common bile duct injury and bile leakage of any cause. Gallstone-related events were defined as complications that occurred during the waiting time.

\section{Data extraction}

Two investigators extracted the following original data from the literature onto a standardized form: the authors, year of publication, type of study, country, definitions of SA-LC and DLC, criteria of pancreatitis, and outcomes of interest. If necessary, the author or authors of the study were contacted to obtain the study data. Conflicts in data abstraction were resolved by consensus and reference to the original article.

\section{Quality assessment}

The Newcastle-Ottawa Scale was used to evaluate the methodological quality of the included trials [18]. The scale ranges from 0 to 9 points; studies with a score of $\geq 6$ are considered to have high methodological quality.

\section{Statistical analysis}

All statistical analyses were performed using Review Manager (RevMan) version 5.3 software (The Cochrane Collaboration, Oxford, United Kingdom). The risk ratio (RR) and 95\% confidence interval (CI) were used to describe dichotomous outcomes. The median and range or interquartile range were used to estimate the mean and standard deviation using a formula from a previous study [19]. The $\mathrm{I}^{2}$ index was used as an indicator of between-study heterogeneity. A fixed-effects model was used when $\mathrm{I}^{2}<50 \%$; otherwise, a random-effects model was used. A two-tailed $p$ value of $<0.05$ was considered statistically significant.

\section{Results}

Selected studies and characteristics of the trials

A flow chart of this study is shown in Fig. 1. The search strategy yielded 1564 papers from the respective search sources, of which 679 duplicate references were excluded. The remaining 885 studies were retrieved to examine their titles and abstracts, resulting in 15 articles that appeared to meet our selection criteria. Of these articles, four were excluded because one study did not provide the criteria of pancreatitis [20] and three studies included patients with severe pancreatitis [21-23]. Finally, 11 trials $[16,20,24-33]$ (4 randomized controlled trials [RCTs] $[16,24,30,32]$ and 7 retrospective studies [20, 25-29, 31, 33]) involving 1833 participants were included in the meta-analysis. 


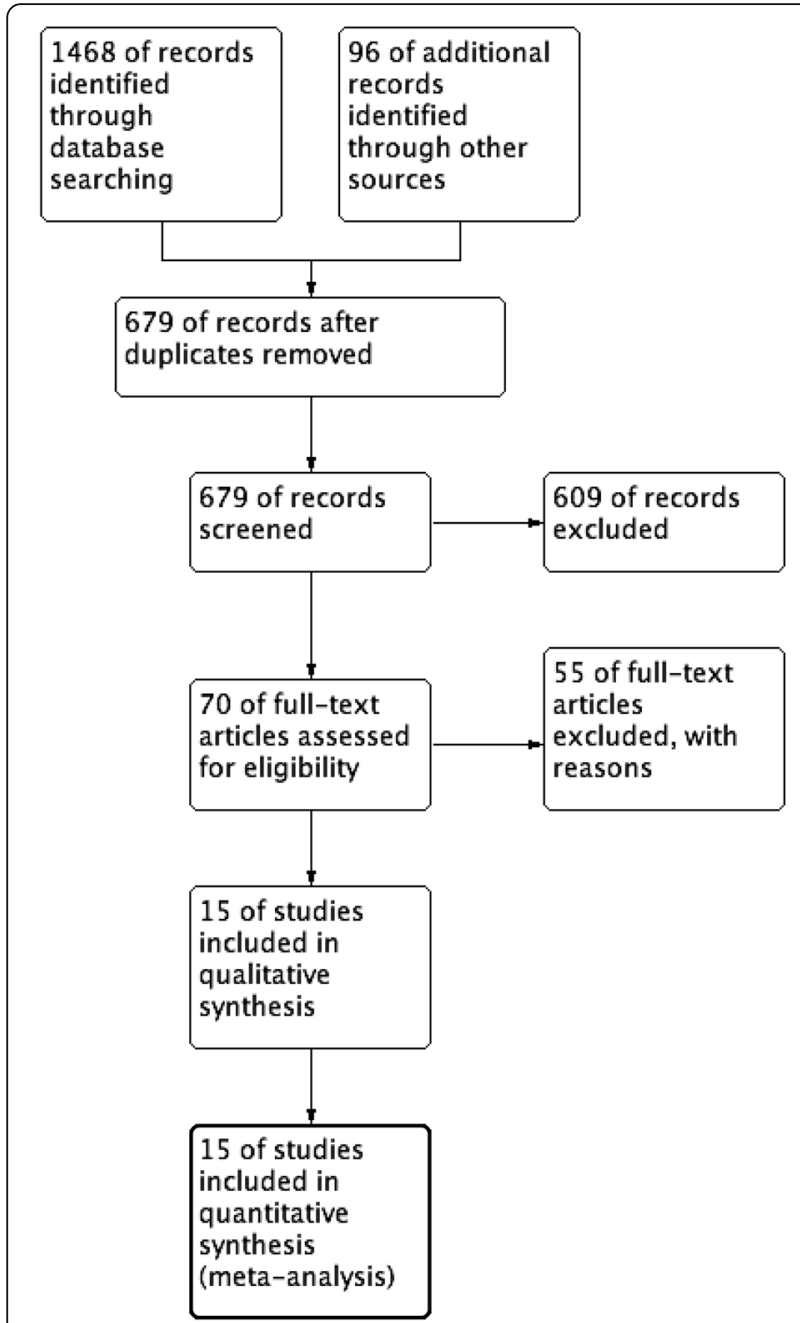

Fig. 1 Flow diagram of the published articles evaluated for inclusion in this meta-analysis
The 1833 patients were divided into either the SA-LC group $(n=913)$ or DLC group $(n=920)$. The sample sizes ranged from 44 to 316 . The countries involved were the United States, Turkey, the United Kingdom, the Netherlands, Italy, Switzerland, Sweden, India, Malaysia, and Canada. The Ranson score and Atlanta classification severity criteria of MABP were applied in the included studies. The main characteristics of the studies included in this meta-analysis are presented in Table 1.

\section{Outcomes}

$\mathrm{COC}$

Data regarding COC were provided in nine studies. The rate of COC was $7.27 \%(59 / 812)$ in the SA-LC group and $6.32 \%$ in the DLC group (55/870). There was no significant difference between the two groups $(\mathrm{RR}=1.24$; 95\% CI, 0.78-1.97; $p=0.36$ ) (Fig. 1a). According to the different criteria of MABP, the subgroup analysis showed no significant differences between the SA-LC group (RR $=1.12 ; 95 \% \mathrm{CI}, 0.77-1.62 ; p=0.56)$ and DLC group (RR $=1.34 ; 95 \% \mathrm{CI}, 0.57-3.14 ; p=0.50)$ in the two subgroups $(p=0.70)$ (Fig. 2b).

\section{Postoperative complications}

All 11 studies provided complete data on postoperative complications. The meta-analysis showed no significant differences in the incidence of postoperative complications between the SA-LC and DLC groups $(\mathrm{RR}=1.06$; 95\% CI, 0.67-1.69; $p=0.80$ ) (Fig. 3a). Similar results were obtained in the subgroup analysis $(\mathrm{RR}=1.18 ; 95 \%$ CI, $0.68-2.06 ; \mathrm{p}=0.56$ vs. $\mathrm{RR}=0.83 ; 95 \% \mathrm{CI}, 0.35-1.95$; $p=0.66)$ (Fig. 3b).

Table 1 Characteritics of included studies

\begin{tabular}{|c|c|c|c|c|c|c|c|c|}
\hline \multirow[t]{2}{*}{ Author } & \multirow[t]{2}{*}{ Country } & \multirow[t]{2}{*}{ Study design } & \multicolumn{2}{|c|}{ Sample } & \multicolumn{2}{|l|}{ Definition } & \multirow[t]{2}{*}{ Criteria of MABP } & \multirow[t]{2}{*}{ NOS } \\
\hline & & & SA-LC & $\mathrm{DLC}$ & SA-LC & DLC & & \\
\hline Aboulian et al. 2010 [24] & USA & $\mathrm{RCT}$ & 25 & 25 & $<48 h$ & $>48 h$ & Ranson score & 8 \\
\hline Aksoy et al. 2017 [25] & Turkey & Retrospective & 75 & 87 & $<3$ days & 4-10 weeks & Ranson scor & 8 \\
\hline Al-Qahtani et al. 2014 & Saudi Arabia & Retrospective & 267 & 83 & Index admission & 6-12 weeks & Ranson score & 7 \\
\hline Costa et al. 2015 [16] & Dutch & $\mathrm{RCT}$ & 128 & 136 & $>3$ days & 25-30 days & Atlanta classification & 8 \\
\hline Falor et al. 2012 [27] & USA & Retrospective & 117 & 186 & $<48 h$ & $>48 h$ & Ranson score & 7 \\
\hline Griniatsos et al. 2005 [28] & UK & Retrospective & 20 & 24 & $<2$ weeks & $>2$ weeks & Ranson score ${ }^{a}$ & 7 \\
\hline Guadagni et al. 2017 [29] & Italy & Retrospective & 98 & 218 & $<3$ days & $>3$ days & Ranson score & 8 \\
\hline Jee et al. 2016 & Malaysia & $\mathrm{RCT}$ & 38 & 34 & Same admission & $>6$ weeks & Atlanta classification & 8 \\
\hline Nebiker et al. 2009 [31] & Switzerland & Retrospective & 32 & 67 & $<14$ days & $>14$ days & Ranson score & 8 \\
\hline Rozh Noel et al. 2018 & Sweden & $\mathrm{RCT}$ & 32 & 34 & Index admission & $>6$ weeks & Atlanta classification & 8 \\
\hline Sinha et al. 2008 [33] & India & Retrospective & 81 & 26 & $<7$ days & $>6$ weeks & Ranson's score & 7 \\
\hline
\end{tabular}

$R C T$ randomized controlled trial, SA-LC same-admission laparoscopic cholecystectomy, DLC delayed laparoscopic cholecystectomy 


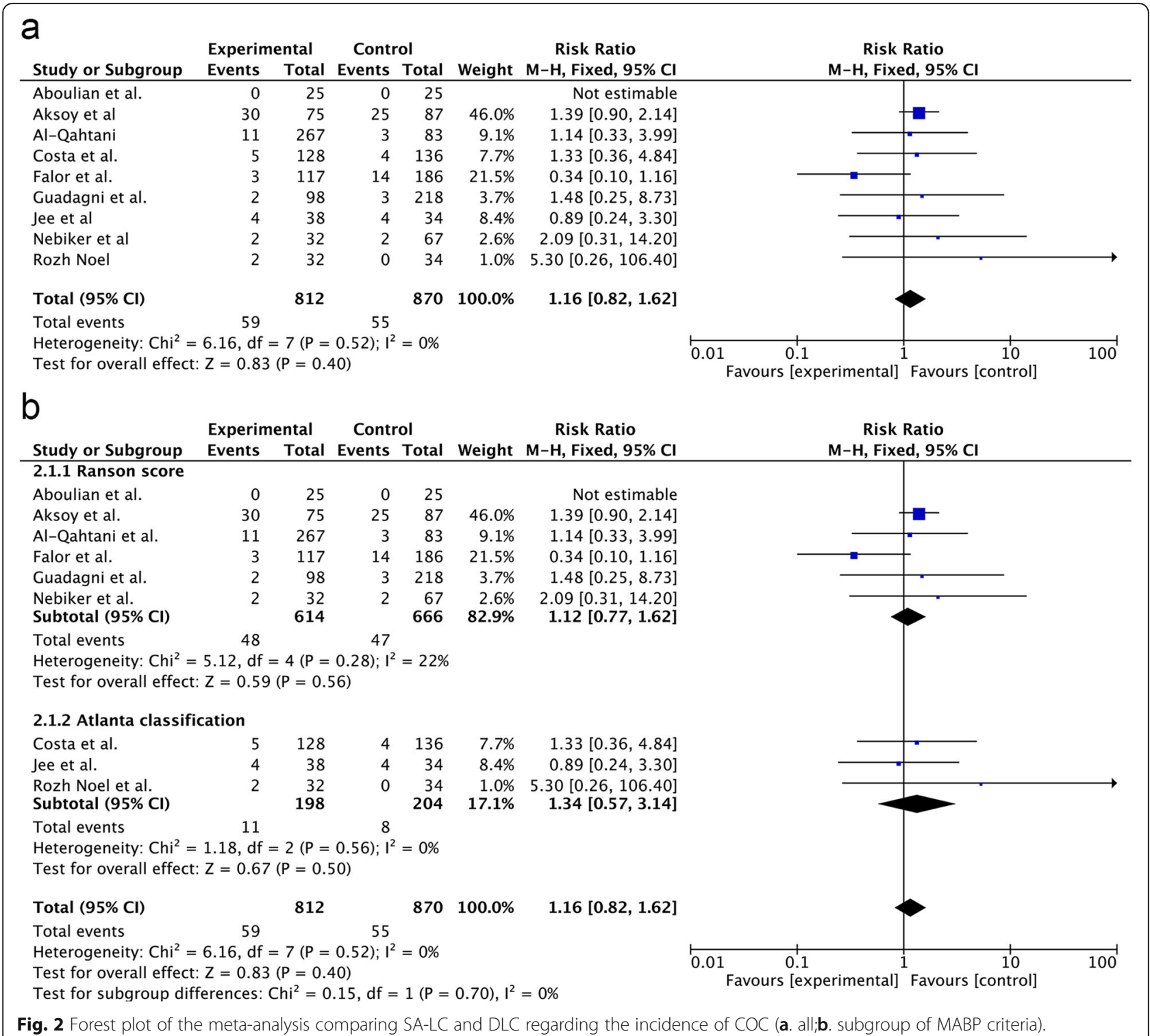

\section{Biliary-related complications}

The incidence of biliary-related complications was 7/913 and $5 / 920$ in the SA-LC and DLC group, respectively $(\mathrm{RR}=1.28 ; 95 \% \mathrm{CI}, 0.42-3.86 ; \mathrm{p}=0.66)$ (Fig. 4a). The result of the Ranson score subgroup analysis showed no significant differences between the SA-LC and DLC groups $(\mathrm{RR}=1.33 ; 95 \% \mathrm{CI}, 0.40-4.43 ; p=0.64)$ (Fig. 4b). Similarly, the incidence of biliary-related complications in the Atlanta classification subgroup analysis was not significantly different between the two groups ( $R R=$ 1.06; 95\% CI, 0.07-16.81; $p=0.97$ ) (Fig. 4b).

OT

The OT was not significantly different between the groups $(\mathrm{RR}=1.57 ; 95 \% \mathrm{CI},-1.58-4.72 ; p=0.33)$ (Fig. 5a). There was no difference in the OT in the Ranson score subgroup analysis $(\mathrm{RR}=2.57 ; 95 \% \mathrm{CI},-0.73-5.87 ; p=0.13)$ and Atlanta classification $(\mathrm{RR}=8.11$; 95\% CI, $-13.16-29.38$; $p=0.45)$ (Fig. 5b).

Los

Seven trials provided data regarding LOS. Our study showed that SA-LC could significantly shorten the LOS $(\mathrm{RR}=-2.08 ; 95 \% \mathrm{CI},-3.17$ to $-0.99 ; p=0.0002)$ (Fig. 6a). In the Ranson subgroup analysis, the LOS in the SA-LC group was shorter than that in the DLC group $(\mathrm{RR}=-3.20 ; 95 \% \mathrm{CI},-4.40$ to $-2.00 ; p<0.00001)$ (Fig. $6 \mathrm{~b})$. In the Atlanta subgroup analysis, the LOS in the SA-LC group was not significantly different from that in the DLC group $(\mathrm{RR}=-0.40 ; 95 \% \mathrm{CI},-0.80-0.01 ; p=$ $0.05)$. There was a significant difference between the two subgroups $(\mathrm{p}=0.0002)$ (Fig. 6b). 


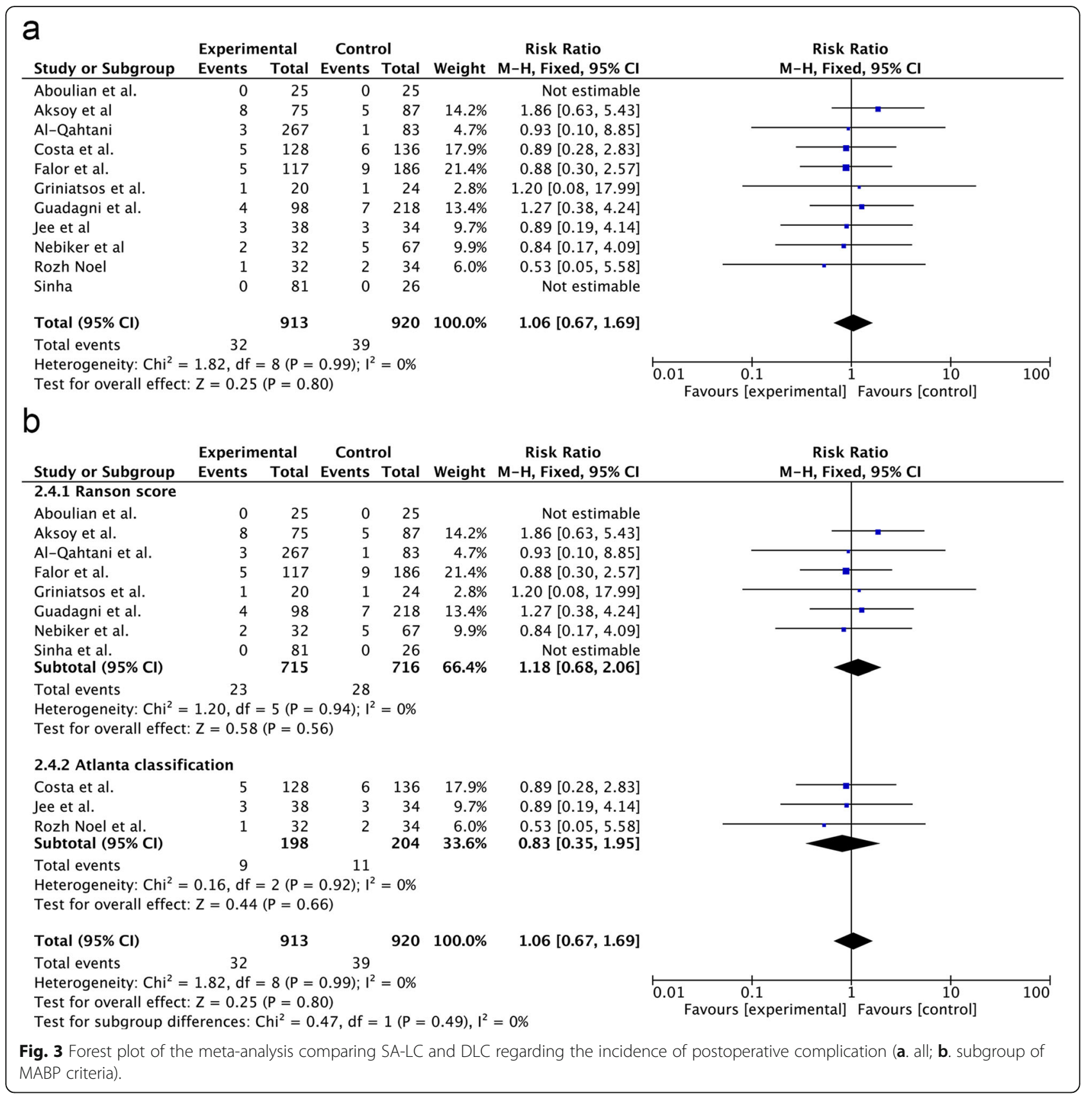

\section{Gallstone-related events}

An analysis of the full text of all included studies showed that in the DLC group, the most common gallstone-related event during the waiting time was biliary colic, which occurred in approximately $13.56 \%$ of patients (86/634). Other events were recurrent acute pancreatitis (54/634), acute cholecystitis (10/ $634)$, jaundice (7/634), and acute cholangitis (4/634). In the included literature, the probability of stone-related events during the waiting period was about 25.39\% (Table 2).

\section{Discussion}

The current study comparing SA-LC with DLC showed the mean rate of $\mathrm{COC}$, rate of postoperative complications, rate of biliary-related complications, and OT. The LOS in the SA-LC group was shorter than that in the DLC group. Given some limitations of the present analysis, future studies on the current topic are recommended.

Several multifactorial scoring systems have been used to classify the severity of acute pancreatitis in the previous studies. Each of these scoring systems has its own 
Table 2 Gallstone-related complications during the waiting time

\begin{tabular}{|c|c|c|c|c|c|c|}
\hline Author (sample of DLC) & $A P$ & $B C$ & $A C$ & Jaundice & Cholangitis & Tota \\
\hline Al-Qahtani et al $(n=267)$ & 9 & & 2 & 7 & 2 & 20 \\
\hline Costa et al $(n=128)$ & 12 & 62 & 2 & & 2 & 78 \\
\hline Falor et al. $(n=117)$ & 1 & & & & & 1 \\
\hline Griniatsos et al. $(n=20)$ & 1 & 6 & & & & 7 \\
\hline Jee et al $(n=38)$ & 2 & 10 & 3 & & & 15 \\
\hline Nebiker et al $(n=32)$ & 9 & 4 & 2 & & & 15 \\
\hline Rozh Noel et al $(n=32)$ & 5 & 4 & & & & 9 \\
\hline Total $(n=634)$ & 54 & 86 & 10 & 7 & 4 & 161 \\
\hline
\end{tabular}

SA-LC same-admission laparoscopic cholecystectomy, $A P$ acute pancreatitis, $B C$ biliary colic, $A C$ acute cholecystitis

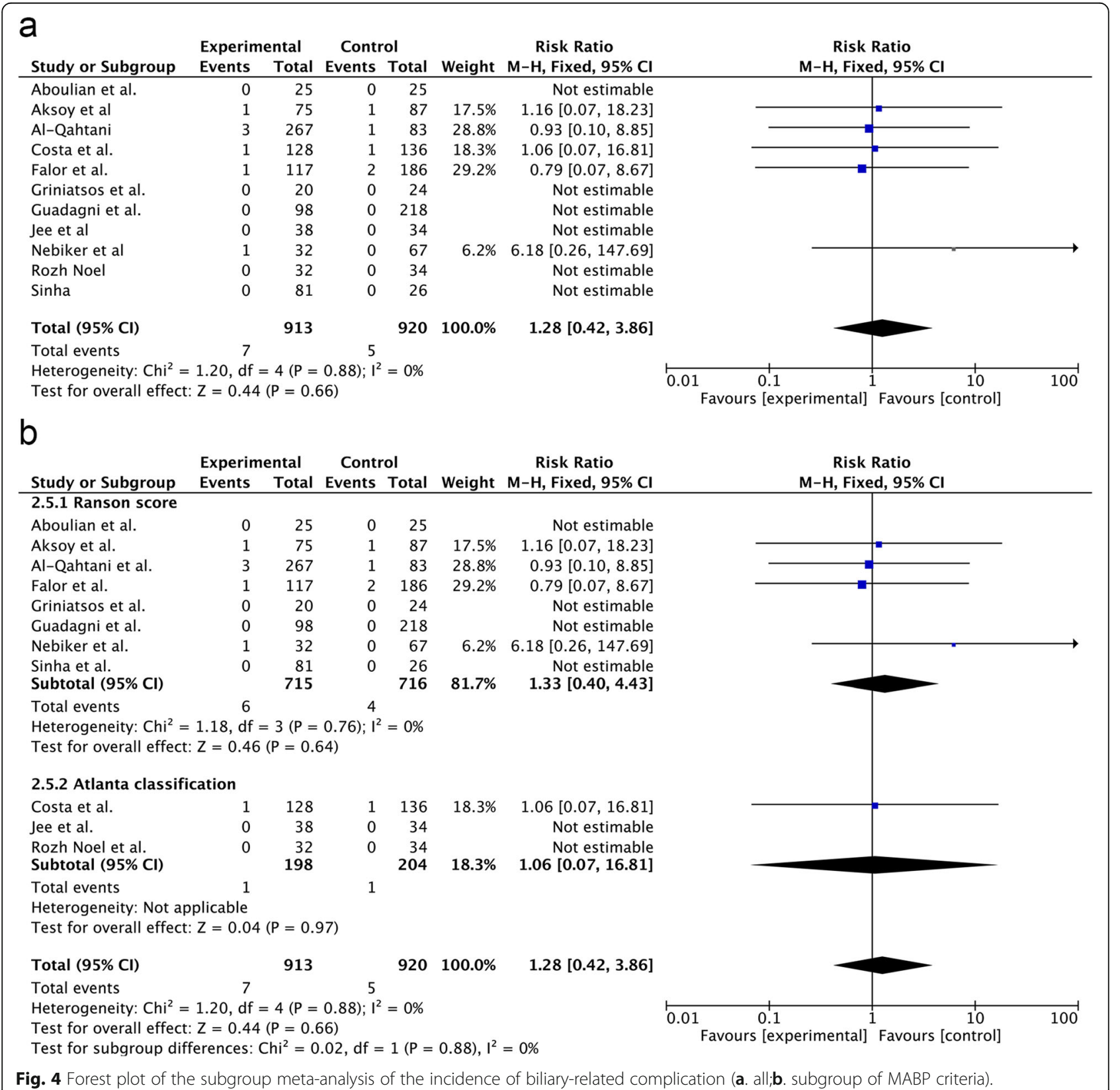




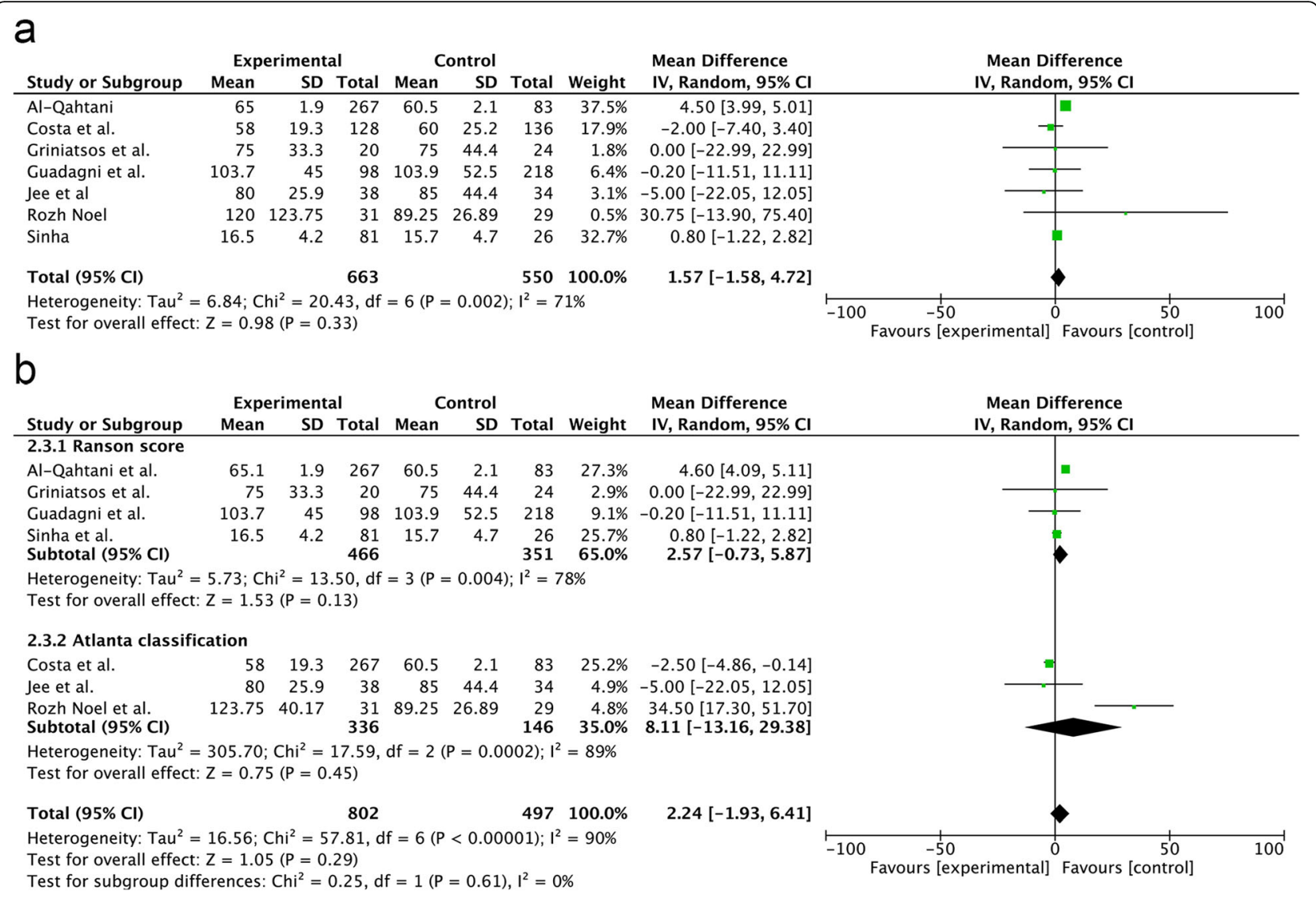

Fig. 5 Forest plot of the meta-analysis comparing SA-LC and DLC regarding the incidence of operative time (a. all;b. subgroup of MABP criteria).

limitations, including low sensitivity and specificity [34]. To our knowledge, this is the first analysis of postoperative complications, OT, and LOS according to different grading criteria. Interestingly, in the Atlanta subgroup analysis, there was no significant difference in hospitalization time between the SA-LC and DLC groups. This difference may be related to the sensitivity and specificity of the different scoring systems. However,in the other outcomes, there were no significantly differences between two subgroups. Future studies should further clarify the impact of these different scoring systems.

LC has become the gold standard surgical approach for the treatment of gallbladder disease [35].The possible increase in the $\mathrm{COC}$ rate is considered to be the reason why many surgeons choose DLC $[36,37]$. A previous study demonstrated that early LC may be more technically challenging because of the edema [33]. In our study, we found that the rate of COC was $7.3 \%$ in the SA-LC group which similar to previous studies. In a study by Aksoy et al., the main reason for $\mathrm{COC}$ in the early group was obscure anatomy (including Calot's triangle), and no significant differences from the delayed group were observed [25]. Interestingly, a study by Sinha showed that dissection of Calot's triangle is more difficult in DLC [33].

However, a certain proportion of complications may still appear after LC, especially in the acute phase [38, 39]. Some researchers believe that LC during the same admission increases the severity of edema caused by pancreatitis [10]. A multicenter study showed that LC within 2 weeks of acute biliary pancreatitis could increase postoperative complications (3\% vs. $1 \%$ ) [36]. In contrast, the current study showed that SA-LC did not increase postoperative complications. A recent review concluded that the rate of postoperative complications in the early LC group was lower than that in the DLC group [40]. One of the most important types of postoperative complications after LC are biliary-related complications, which have a negative impact on patient survival and quality of life $[41,42]$. Prior studies have reported rates of biliary-related complications ranging from 0.2 to $1.5 \%$ after LC $[43,44]$. The results of a cohort study showed that the incidence of major complications associated with SA-LC, including common bile duct injury and bile leakage, was twice that associated 


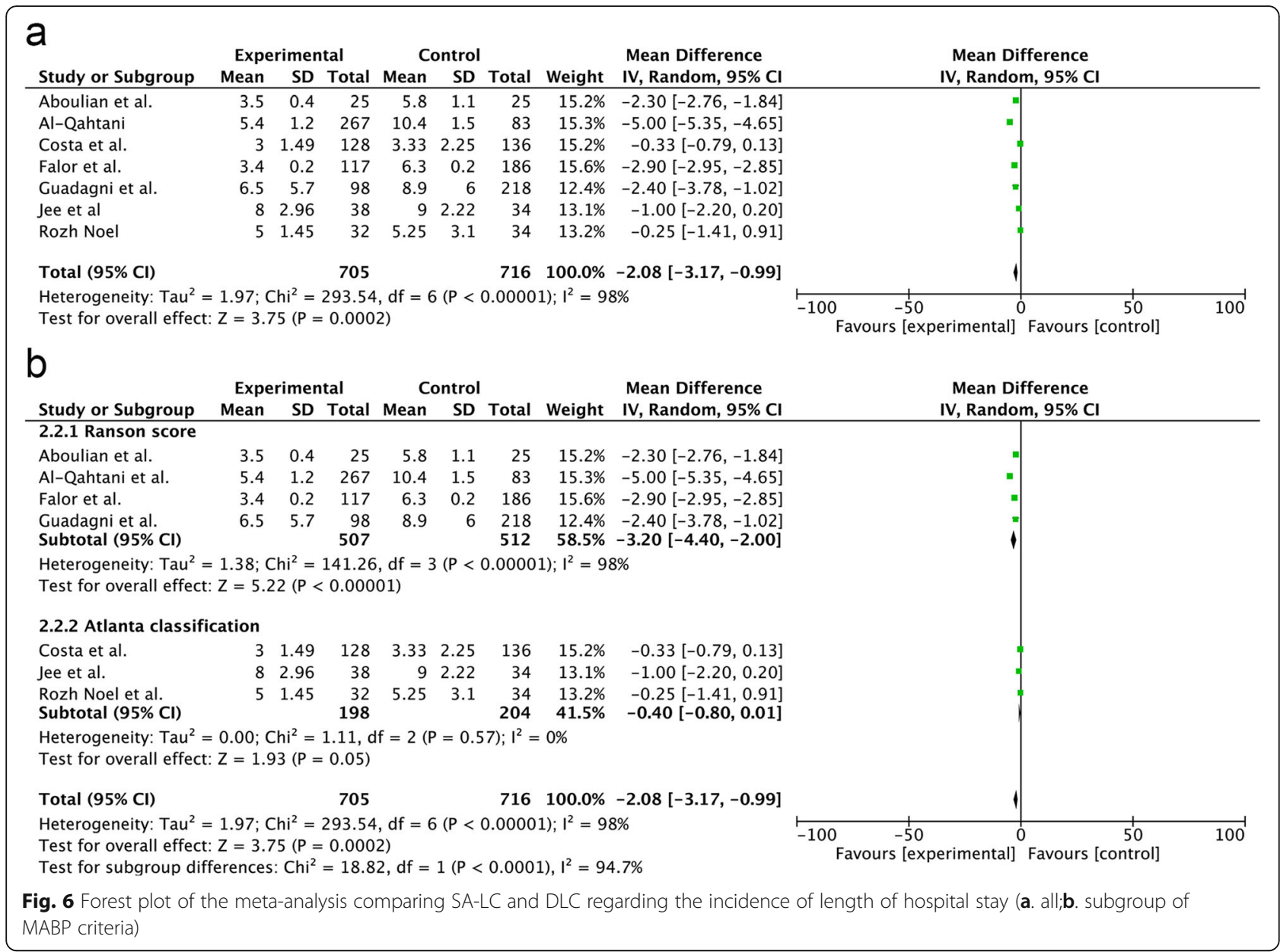

with DLC [36]. However, the sample of patients with major complications was small in this previous study. In the present study, the analysis of biliary-related complications showed no significant differences. Unlike these previous studies, our meta-analysis excluded trials involving patients with severe pancreatitis. LC performed in patients with severe pancreatitis may be unsafe [45].

Surgical time is an indicator of the degree of difficulty in surgery. Similar to previous studies, the present study showed that the timing of LC did not affect the surgical time. Only a few studies provided complete data regarding the mean and standard deviation of the LOS, and we estimated the data using a formula. Therefore, the conclusions regarding the OT and hospital stay still need to be interpreted with caution.

High readmission rates were found in previous studies, ranging from 15 to $29 \%$ [8, 10, 46-49]. Gallstone-related complications included acute cholecystitis, recurrent pancreatitis, and biliary colic. Although biliary colic is the most common complication during the waiting period, recurrent pancreatitis remains the most serious event and reason for readmission [6]. In an up-to-date large-scale RCT, the rates of readmission for gallstone-related complications was $12 \%$ in the DLC group [16]. A nationwide analysis showed that readmission for acute pancreatitis is most often due to recurrent acute pancreatitis [6]. In the present study, the probability of recurrent pancreatitis reached $8.5 \%$. Our analysis of these differences may be related to the fact that in a retrospective study, surgeons are able to perform LC during hospitalization in patients who are susceptible to recurrent pancreatitis.

Limitations: First, despite the fact that LC was performed during the same admission, the specific OT was different. Second, of the included studies, only four were RCTs; the rest were retrospective studies, and heterogeneity was present among these retrospective studies. Third, some of the research data were obtained using a formula. A large-scale RCT is currently in progress [50].

\section{Conclusions}

In summary, SA-LC for MABP can reduce the hospital LOS and does not increase the incidence of 
postoperative complications. However, this conclusion needs to be verified by higher-quality research.

\section{Abbreviations}

COC: Conversion to open cholecystectomy; DLC: Delayed laparoscopic cholecystectomy; LC: Laparoscopic cholecystectomy; LOS: Length of stay; MABP: Mild acute biliary pancreatitis; OT: Operative time; RR: Risk ratio; SA-LC: Same-admission laparoscopic cholecystectomy

\section{Acknowledgments}

We thank Angela Morben, DVM, ELS, from Liwen Bianji, Edanz Editing China (www.liwenbianji.cn/ac), for editing the English text of a draft of this manuscript.

\section{Funding}

The authors have no grant or financial support to report.

\section{Availability of data and materials}

The datasets analyzed during the current study available from the corresponding author on reasonable request

\section{Authors' contributions}

YXL designed the research, analyzed the data and wrote the manuscript; YXC HFJ, XJ, BC and DL collected literatures and conducted the analysis of pooled data; YXL conceived and designed the research, and revised the manuscript as corresponding author. All authors read and approved the final manuscript.

\section{Ethics approval and consent to participate} Not applicable.

\section{Consent for publication}

Not applicable.

\section{Competing interests}

The authors declare that they have no competing interests.

\section{Publisher's Note}

Springer Nature remains neutral with regard to jurisdictional claims in published maps and institutional affiliations.

Received: 13 July 2018 Accepted: 8 November 2018

Published online: 29 November 2018

\section{References}

1. Peery AF, Crockett SD, Barritt AS, Dellon ES, Eluri S, Gangarosa LM, Jensen ET, Lund JL, Pasricha S, Runge T, et al. Burden of gastrointestinal, liver, and pancreatic diseases in the United States. Gastroenterology. 2015;149(7):1731-41.

2. Banks PA, Freeman ML. Practice parameters Committee of the American College of G: practice guidelines in acute pancreatitis. Am J Gastroenterol. 2006;101(10):2379-400.

3. Tenner S, Baillie J, DeWitt J, Vege SS. American College of Gastroenterology guideline: management of acute pancreatitis. Am J Gastroenterol. 2013; 108(9):1400-15 1416

4. Gullo L, Pezzilli R. Acute pancreatitis is unlikely after morphine administration. Dig Liver Dis. 2000;32(1):74.

5. Yadav D, Lowenfels AB. The epidemiology of pancreatitis and pancreatic cancer. Gastroenterology. 2013;144(6):1252-61.

6. Garg SK, Campbell JP, Anugwom C, Wadhwa V, Singh R, Gupta N, Sanaka MR. Incidence and predictors of readmissions in acute pancreatitis: a Nationwide analysis. Pancreas. 2018;47(1):46-54.

7. Moreau JA, Zinsmeister AR, Melton $\sqcup$ 3rd, DiMagno EP. Gallstone pancreatitis and the effect of cholecystectomy: a population-based cohort study. Mayo Clin Proc. 1988;63(5):466-73.

8. Yadav D, O'Connell M, Papachristou GI. Natural history following the first attack of acute pancreatitis. Am J Gastroenterol. 2012;107(7):1096-103.

9. Vetrhus M, Berhane T, Soreide O, Sondenaa K. Pain persists in many patients five years after removal of the gallbladder: observations from two randomized controlled trials of symptomatic, noncomplicated gallstone disease and acute cholecystitis. J Gastrointest Surg. 2005;9(6):826-31.
10. van Baal MC, Besselink MG, Bakker OJ, van Santvoort HC, Schaapherder AF, Nieuwenhuijs VB, Gooszen HG, van Ramshorst B, Boerma D. Timing of cholecystectomy after mild biliary pancreatitis: a systematic review. Ann Surg. 2012;255(5):860-6.

11. American Gastroenterological Association Institute on. "Management of Acute Pancreatits" clinical P, economics C, board AGAIG: AGA Institute medical position statement on acute pancreatitis. Gastroenterology. 2007; 132(5):2019-21.

12. Working Party of the British Society of G. Association of Surgeons of great B, Ireland, pancreatic Society of Great B, Ireland, Association of Upper GISoGB, Ireland: UK guidelines for the management of acute pancreatitis. Gut. 2005;54(3):iii1-9.

13. IAP/APA evidence-based guidelines for the management of acute pancreatitis. Pancreatology. 2013;13(4 2):1-15.

14. Forsmark CE, Baillie J, Practice AGAIC, Economics C, Board AGAIG. AGA Institute technical review on acute pancreatitis. Gastroenterology. 2007; 132(5):2022-44

15. Hernandez V, Pascual I, Almela P, Anon R, Herreros B, Sanchiz V, Minguez M Benages $A$. Recurrence of acute gallstone pancreatitis and relationship with cholecystectomy or endoscopic sphincterotomy. Am J Gastroenterol. 2004; 99(12):2417-23.

16. da Costa DW, Bouwense SA, Schepers NJ, Besselink MG, van Santvoort HC, van Brunschot S, Bakker OJ, Bollen TL, Dejong CH, van Goor H, et al. Sameadmission versus interval cholecystectomy for mild gallstone pancreatitis (PONCHO): a multicentre randomised controlled trial. Lancet. 2015; 386(10000):1261-8.

17. Liberati A, Altman DG, Tetzlaff J, Mulrow C, Gotzsche PC, loannidis JP, Clarke M, Devereaux PJ, Kleijnen J, Moher D. The PRISMA statement for reporting systematic reviews and meta-analyses of studies that evaluate health care interventions: explanation and elaboration. J Clin Epidemiol. 2009;62(10):e1-34

18. Stang A. Critical evaluation of the Newcastle-Ottawa scale for the assessment of the quality of nonrandomized studies in meta-analyses. Eur J Epidemiol. 2010;25(9):603-5.

19. Wan X, Wang W, Liu J, Tong T. Estimating the sample mean and standard deviation from the sample size, median, range and/or interquartile range. BMC Med Res Methodol. 2014;14:135.

20. McCullough LK, Sutherland FR, Preshaw R, Kim S. Gallstone pancreatitis: does discharge and readmission for cholecystectomy affect outcome? HPB (Oxford). 2003;5(2):96-9.

21. Egin S, Yesiltas M, Gokcek B, Tezer H, Karahan SR. Early laparoscopic cholecystectomy following acute biliary pancreatitis expedites recovery. Ulus Travma Acil Cerrahi Derg. 2017;23(6):495-500.

22. Borreca D, Bona A, Bellomo MP, Borasi A. P DEP: timing of cholecystectomy in acute biliary pancreatitis: is it still reasonable to wait? Minerva Chir. 2016;71(1):31-7

23. Ito $\mathrm{K}$, Ito $\mathrm{H}$, Whang EE. Timing of cholecystectomy for biliary pancreatitis: do the data support current guidelines? J Gastrointest Surg. 2008;12(12):2164-70.

24. Aboulian A, Chan T, Yaghoubian A, Kaji AH, Putnam B, Neville A, Stabile BE, de Virgilio C. Early cholecystectomy safely decreases hospital stay in patients with mild gallstone pancreatitis: a randomized prospective study. Ann Surg. 2010;251(4):615-9.

25. Aksoy F, Demiral G, Ekinci O. Can the timing of laparoscopic cholecystectomy after biliary pancreatitis change the conversion rate to open surgery? Asian J Surg. 2017.

26. Al-Qahtani HH, Alam MK, Al-Akeely MH, Al-Salamah SM. Cholecystectomy without intraoperative cholangiogram in gallstone pancreatitis. Saudi Med J. 2011;32(7):714-7.

27. Falor AE, de Virgilio C, Stabile BE, Kaji AH, Caton A, Kokubun BA, Schmit PJ, Thompson JE, Saltzman DJ. Early laparoscopic cholecystectomy for mild gallstone pancreatitis: time for a paradigm shift. Arch Surg. 2012;147(11):1031-5.

28. Griniatsos J, Karvounis E, Isla A. Early versus delayed single-stage laparoscopic eradication for both gallstones and common bile duct stones in mild acute biliary pancreatitis. Am Surg. 2005;71(8):682-6.

29. Guadagni S, Cengeli I, Palmeri M, Bastiani L, Bertolucci A, Modesti M, Galatioto C, Chiarugi M. Early cholecystectomy for non-severe acute gallstone pancreatitis: easier said than done. Minerva Chir. 2017;72(2): 91-7.

30. Jee $\mathrm{SL}$, Jarmin R, Lim KF, Raman K. Outcomes of early versus delayed cholecystectomy in patients with mild to moderate acute biliary pancreatitis: a randomized prospective study. Asian J Surg. 2018:41(1):47-54 
31. Nebiker CA, Frey DM, Hamel CT, Oertli D, Kettelhack C. Early versus delayed cholecystectomy in patients with biliary acute pancreatitis. Surgery. 2009; 145(3):260-4.

32. Noel R, Arnelo U, Lundell L, Hammargvist F, Jumaa H, Enochsson L, Sandblom G. Index versus delayed cholecystectomy in mild gallstone pancreatitis: results of a randomized controlled trial. HPB (Oxford). 2018;20(10):932-8.

33. Sinha R. Early laparoscopic cholecystectomy in acute biliary pancreatitis: the optimal choice? HPB (Oxford). 2008;10(5):332-5.

34. Khanna AK, Meher S, Prakash S, Tiwary SK, Singh U, Srivastava A, Dixit VK. Comparison of Ranson, Glasgow, MOSS, SIRS, BISAP, APACHE-II, CTSI scores, IL-6, CRP, and Procalcitonin in predicting severity, organ failure, pancreatic necrosis, and mortality in acute pancreatitis. HPB Surg. 2013;2013:367581.

35. Genc V, Sulaimanov M, Cipe G, Basceken SI, Erverdi N, Gurel M, Aras N, Hazinedaroglu SM. What necessitates the conversion to open cholecystectomy? A retrospective analysis of 5164 consecutive laparoscopic operations. Clinics (Sao Paulo, Brazil). 2011;66(3):417-20.

36. Johnstone M, Marriott P, Royle TJ, Richardson CE, Torrance A, Hepburn E, Bhangu A, Patel A, Bartlett DC, Pinkney TD. The impact of timing of cholecystectomy following gallstone pancreatitis. Surgeon. 2014;12(3):134-40,

37. Kelly TR, Wagner DS. Gallstone pancreatitis: a prospective randomized trial of the timing of surgery. Surgery. 1988;104(4):600-5.

38. Livingston DH, Capko DM, Elcavgae J, Raina S, Machiedo GW, Rush BF Jr. Laparoscopic cholecystectomy in the inner-city hospital. Am Surg. 1994;60(12):971-4

39. Yamashita Y, Takada T, Hirata K. A survey of the timing and approach to the surgical management of patients with acute cholecystitis in Japanese hospitals. J Hepato-Biliary-Pancreat Surg. 2006;13(5):409-15.

40. Yang DJ, Lu HM, Guo Q, Lu S, Zhang L, Hu WM. Timing of laparoscopic cholecystectomy after mild biliary pancreatitis: a systematic review and meta-analysis. J Laparoendosc Adv Surg Tech A. 2018;28(4):379-88.

41. Bouras G, Burns EM, Howell AM, Bagnall NM, Lee H, Athanasiou T, Darzi A. Systematic review of the impact of surgical harm on quality of life after general and gastrointestinal surgery. Ann Surg. 2014;260(6):975-83.

42. Berci G, Hunter J, Morgenstern L, Arregui M, Brunt M, Carroll B, Edye M, Fermelia D, Ferzli G, Greene F, et al. Laparoscopic cholecystectomy: first, do no harm; second, take care of bile duct stones. Surg Endosc. 2013; 27(4):1051-4.

43. Tornqvist B, Zheng Z, Ye W, Waage A, Nilsson M. Long-term effects of iatrogenic bile duct injury during cholecystectomy. Clin Gastroenterol Hepatol. 2009;7(9):1013-8 quiz 1915.

44. Tornqvist B, Stromberg C, Akre O, Enochsson L, Nilsson M. Selective intraoperative cholangiography and risk of bile duct injury during cholecystectomy. Br J Surg. 2015;102(8):952-8.

45. Nealon WH, Bawduniak J, Walser EM. Appropriate timing of cholecystectomy in patients who present with moderate to severe gallstone-associated acute pancreatitis with peripancreatic fluid collections. Ann Surg. 2004;239(6):741-9 discussion 749-751.

46. Vipperla K, Papachristou Gl, Easler J, Muddana V, Slivka A, Whitcomb DC, Yadav D. Risk of and factors associated with readmission after a sentinel attack of acute pancreatitis. Clin Gastroenterol Hepatol. 2014;12(11):1911-9.

47. Yadav D, Lee E, Papachristou Gl, O'Connell M. A population-based evaluation of readmissions after first hospitalization for acute pancreatitis. Pancreas. 2014;43(4):630-7.

48. Suchsland T, Aghdassi A, Kuhn K, Simon P, Lerch MM, Mayerle J, Flessa S. Predictive factors for and incidence of hospital readmissions of patients with acute and chronic pancreatitis. Pancreatology. 2015;15(3):265-70.

49. Baroldi G. Distribution of arterio-atherosclerotic obstructive lesions in coronary arteries. Vasc Surg. 1974;8(1):53-9.

50. Mueck KM, Wei S, Liang MK, Ko TC, Tyson JE, Kao LS. Protocol for a randomized trial of the effect of timing of cholecystectomy during initial admission for predicted mild gallstone pancreatitis at a safety-net hospital. Trauma Surg Acute Care Open. 2018;3(1-4):e000152.

Ready to submit your research? Choose BMC and benefit from:

- fast, convenient online submission

- thorough peer review by experienced researchers in your field

- rapid publication on acceptance

- support for research data, including large and complex data types

- gold Open Access which fosters wider collaboration and increased citations

- maximum visibility for your research: over $100 \mathrm{M}$ website views per year

At $\mathrm{BMC}$, research is always in progress.

Learn more biomedcentral.com/submissions 